\title{
Artificial selection of insects to bioconvert pre-consumer organic wastes. A review
}

\author{
Trevor M. Fowles ${ }^{1} \cdot$ Christian Nansen $^{1}$ (]) \\ Accepted: 10 April 2019 / Published online: 8 May 2019 \\ (C) The Author(s) 2019
}

\begin{abstract}
As the human population continues to grow, so too do the concerns regarding the sustainability of waste management from our food production systems. Faced with limited environmental resources for food production, issues related to food loss and waste are critical in mitigating challenges stemming from projected population growth and long-term food security and sustainability. The potential for using insects to consume organic waste materials and convert them into feed for animal, biofuels, and other valuable secondary products is gaining momentum as both a research discipline and as a business opportunity. Here, this ecosystem service is referred to as "insects as bioconverters of organic waste." Scientific reviews of this topic have mainly focused on the challenges associated with development of commercial scale systems. To compliment existing reviews, we address this exciting topic from an artificial selection perspective, as we review and discuss aspects associated with targeted breeding and adaptation of both gut microbial communities and host insects themselves. We describe the "ideal insect bioconverter," insects uniquely equipped to convert wastes into biomass and other valuable secondary products, and we present the current knowledge and existing research gaps towards the development of such organisms. We conclude that (1) targeted breeding of insects and their gut microbes can produce tailored insect lineages for bioconversion of specific waste streams; (2) research is needed to take full advantage of the existing insect diversity to identify new candidate species for bioconversion; and (3) further research into insect-gut microbial complexes will likely provide important insight into ways insects can be used as sustainable bioconverters of highly specialized waste streams.
\end{abstract}

Keywords Bioconversion · Sustainable agriculture $\cdot$ Breeding $\cdot$ Adaptive plasticity $\cdot$ Entomophagy $\cdot$ Microbiome $\cdot$ Industrial entomology $\cdot$ Organic residues $\cdot$ Food waste

\section{Contents}

1. Introduction

1.1 The problem

1.2 The solution

1.3 Artificial selection

1.4 The "ideal insect bioconverter"

1.5 Insect species currently used as bioconverters

1.6 The role of gut symbionts

1.7 Bioconversion outputs

2. Substantive gains from artificial selection and discovery 2.1. Mining insect diversity

Christian Nansen

chrnansen@ucdavis.edu

1 Agronomy for Sustainable Development, Department of Entomology and Nematology, University of California, UC Davis Briggs Hall, Room 367, Davis, CA 95616, USA
2.2. Breeding program design

2.3 Adaptive phenotypic plasticity

2.4 How to monitor and quantify adaptive phenotypic plasticity

3 Conclusion

Funding information

References

\section{Introduction}

\subsection{The problem}

It is estimated that by 2030, USA's agricultural production and industrial processing of food will generate between 145 and 602 gigatons of organic waste annually (Perlack et al. 2005; Turhollow et al. 2014). Assuming a population of 359.4 million (Colby and Ortman 2017), this amounts to approximately 
$4.5 \mathrm{~kg}$ per day per person! Food wastes are often differentiated as either pre- or post-consumer waste, with the former including waste streams derived from losses incurred during growth, harvest, transport, processing, and storage (Parfitt et al. 2010). Conversely, post-consumer wastes are derived from losses incurred at the consumer level, including over- or inappropriate purchasing, storage, preparation, portioning, and cooking (Parfitt et al. 2010). While post-consumer food waste is certainly a global concern, this review treats only pre-consumer organic wastes, as they are often less covered in reviews of insect bioconversion (Surendra et al. 2016; Wang and Shelomi 2017; Diener et al. 2011; Čičková et al. 2015), do not have the same regulatory and health concerns (Codex Alimentarius Commission 2014), and are more chemically and physically diverse (Parfitt et al. 2010). Specifically, pre-consumer organic wastes are by-products in the food supply chain based on materials not designated for human consumption, and they include (1) non-marketable but edible food (damaged and misshapen); (2) food spoilage at production sites; (3) byproducts from primary food processing, including stems, leaves, hulls, seeds, skins, and pulps generated from cleaning, de-hulling, pounding, grinding, packaging, soaking, winnowing, drying, sieving, and milling; (4) by-products from secondary food processing - the cuttings, crumbs, and remains generated from mixing, cooking, frying, molding, cutting, and extrusion (Parfitt et al. 2010); and (5) non-food postharvest by-products associated with orchard and field cropsthe chips, slash, wood, fibers, and stovers (Hoogwijk et al. 2003) (Fig. 1).

Each combination of crop and its method of production, processing, packaging, storage, and distribution generates a unique set of pre-consumer organic wastes. For example, residuals from pre-consumer processing of fruit and vegetables for juice can include leaves, peels, pulps, and seeds (Rezzadori et al. 2012), each with different chemical and physical properties. With over 6000 crop species in production globally (Hanelt 2001), and a wide range of processed goods, the diversity of organic waste streams is immense (Colby and Ortman 2017). Despite growing legal restrictions, some preconsumer organic wastes are still disposed in landfills and considered a problem rather than an economic opportunity (Lou and Nair 2009). Disposal of pre-consumer organic wastes in compost and landfilling operations generate considerable greenhouse gas emissions and other environmental pollutants (Eriksson et al. 2015; Schott et al. 2016). Therefore, developing innovative ways to use pre-consumer organic wastes is important for reasons of material efficiency and product development as well as pollution prevention and economic gain. Currently, about 3.73 billion hectares, a staggering $\sim 75 \%$ of the planets arable land!, is dedicated to livestock grazing (Foley et al. 2011), and the demand for meat is expected to grow $58 \%$ by 2050 (McLeod 2011). Consequently, there is a dire need for alternative sources of proteins and fats to meet the growing human demand, and use of insect biomass represents an opportunity to meet this growing demand. The potential of using insects to produce proteins and fats is of particular interest when tied directly to development of more sustainable waste management practices. Moreover, preconsumer organic wastes can be consumed as a feedstock by insects, which "bioconvert" the waste into valuable products (Wang and Shelomi 2017; Smetana et al. 2016; Oonincx and De Boer 2012; Vantomme et al. 2012).

\subsection{The solution}

The production of pre-consumer organic wastes may be considered a waste problem, but they also represent potentially significant resources and business opportunities due to their richness in nutrients and active compounds (Brar et al. 2013). An illustrative example of this type of transformation is how whey protein from cheese production represented a major problem for the diary industries up until the 1980s, with farmers paying for disposal or reuse as fertilizer. In recent years, the protein powder industry has recognized the value of whey and is now willing to pay for this high-value protein source. Moreover, novel markets and industries may emerge through innovative utilization of existing organic "waste products" and in the process eliminate waste streams and create jobs and industries. Other examples include use of organic wastes as substrate for mushroom production, compost, energy production, or fillers in animal feed (e.g., insect biomass) (Surendra et al. 2016; Lou and Nair 2009; Kusch et al. 2015; Kabongo 2013; Lim et al. 2016; California Biomass Collaborative 2012; Zweigle 2010).

Similar to conventional livestock production, the insects themselves can be commercialized as bulk biomass to be added to animal feed or human food, and/or specific compounds can be extracted from their biomass for industrial, pharmaceutical, or energy (biofuel) purposes, such as proteins and fats (Surendra et al. 2016; Wang and Shelomi 2017; Kagata and Ohgushi 2012). In addition, the left-over material [insect molts and feces (frass) and left-over waste material] may be processed and commercialized as high-value soil amendments. Current insect bioconversion facilities have the capacity to accept as much as 250 tons of food waste per day (www.agriprotein. com), so development and adoption of insect-based waste management solutions is not a thing of the future but unfolding and gaining momentum. A crucial aspect of large-scale use of insects as bioconverters of pre-consumer organic wastes is their "bioconversion rate," which is a quantitative measure of the input:output ratio (Oonincx et al. 2015; Wilkinson 2011; Lundy and Parrella 2015). The bioconversion rate can be measured based on a number of variables, including energy, protein, and fat, and a low bioconversion rate implies high efficiency. In livestock nutrition, it is common to calculate the bioconversion rate based on the nutrient or energy content of feed material 
Fig. 1 White and red wine pomace - examples of preconsumer organic food waste. Depending on the processing method, pre-consumer food wastes can be quite variable in their final composition. Four examples are presented here. a Freshly pressed white wine pomace, rich in sugars, with considerable content of stems and leaves. b Freshly fermented red wine pomace with relatively high content of alcohol and low sugar content, with relatively low content of stems and leaves due to pre-fermentation de-stemming. c, d Samples of white wine pomace (left) and red wine pomace (right) without stems and leaves
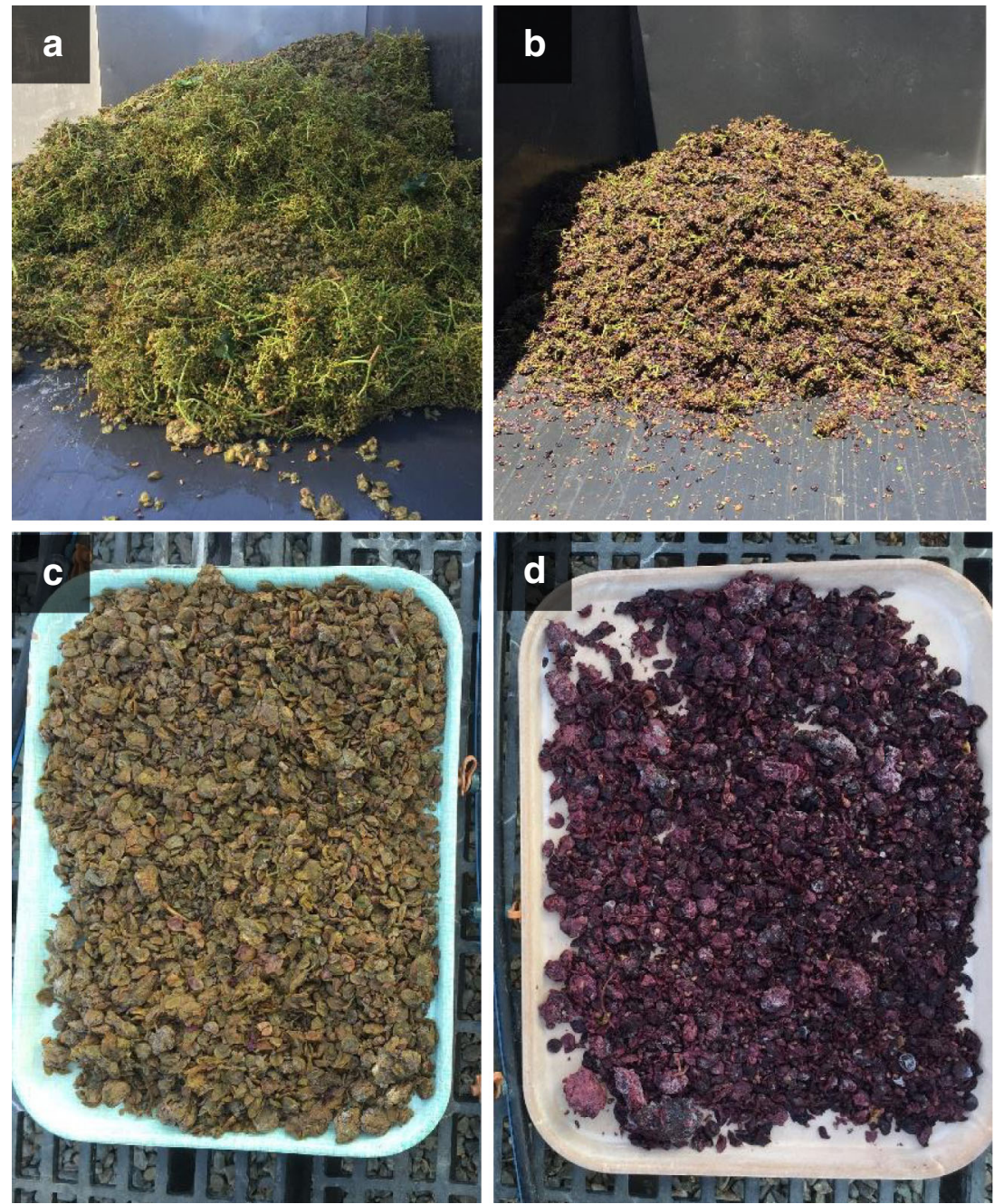

compared to the nutrient or energy content of meat or milk produced (Wilkinson 2011). Such a calculation is partially incomplete, as considerable energy, fertilizer, labor, and other inputs often were used to produce and process the feed materials. We are unaware of any direct comparisons of bioconversion rates of insects and typical livestock animals. That is, to accurately compare their conversion rates, the exact same feed material should be given to insects and, for instance, cows or chicken, and their growth in biomass as well as their production (eggs and milk) should be quantified. Without such true comparisons, it is difficult to accurately compare bioconversion rates. Regarding conversion rates of insects versus traditional livestock, it is also important to emphasize that entire insect bodies can typically be used, while only the meat from vertebrate livestock is commercialized. Thus, the proportion of usable biomass (compared to bines, hides, internal organs, etc. in vertebrate livestock) is generally markedly higher for insects. Finally, the protein content of insects, such as houseflies (Musca domestica), mealworms (Tenebrio molitor), and crickets (Acheta domesticus), is typically 40-70\% (Makkar et al. 2014). For comparison, the protein content of a whole chicken or cow is typically $\sim 55 \%$ and $\sim 40 \%$, respectively (Van Huis 2013). Thus, from a bioconversion standpoint, there are strong arguments for focusing on insects as bioconverters of our current and future pre-consumer organic wastes.

In this review, we argue that development, use, and commercialization of tailored/customized insect-microbial systems to specific pre-consumer organic wastes are at the brink of becoming a serious and profitable business sector and also an accepted research discipline. Moreover, we show that insects (and their gut microbials) can and will play a major role in the development of sustainable management plans for preconsumer organic wastes. We review this exciting area from the perspectives and applications of evolutionary and ecological theory to insect breeding.

\subsection{Artificial selection}

Natural selection may be defined as the process, in which variable and heritable fitness-promoting traits are selected for within a population of a given species to increase the fitness of individuals in the following generations (Endler 
1986). In nature, complex community interactions drive natural selection, and these interactions are underpinned by spatio-temporal dynamics of the given environment. Consequently, "artificial selection" of insects is defined as deliberate anthropogenic control and manipulation of selection forces to promote a particular evolutionary outcome (optimization of an insect population to serve as bioconverter of a specific organic waste product) (Zeder 2012; Meyer et al. 2012). While modern phenotypes (observable traits) of only a few insect species are regarded as the outcome of artificial selection (i.e., domesticated honey bees (Apis mellifera L.), flightless mulberry silkworm (Bombyx mori L.), and resinous lac bug [Kerria lacca (Kerr)] (Melillo 2013)), the potential of artificial selection to improve insect lineages has been discussed for decades (Hoy 1976). In addition, this endeavor is greatly facilitated by copious research and development in the mass rearing of insects, (Ortiz et al. 2016) with notable examples including production of sterile insects and natural enemies for biocontrol, (Dyck et al. 2006) production of medically important species for research, and insect biomass for animal and human consumption (Wang and Shelomi 2017; Salomone et al. 2017). However, the recent recognition of insects as potential bioconverters of pre-consumer organic wastes is a new and exciting area. Moreover, progress in use of insects for bioconversion of wastes will benefit, if mass rearing insects is viewed through a particular lens, (Jensen et al. 2017) in which evolutionary processes and gut microbe-host interactions play major roles.

\subsection{The "ideal insect bioconverter"}

As decomposers and herbivores, the diversity of insect species includes groups that are highly specialized in their ability to thrive on different organic substrates and under specialized environmental conditions (Futuyma and Agrawal 2009). Moreover, some natural host substrates resemble pre-consumer organic wastes, in terms of moisture content, digestibility, and nutritional composition (Smetana et al. 2016). In addition, insect functional diversity (the behavioral and the ecological services they provide) can be exploited to substitute mechanical and/or chemical steps in conventional waste processing,(Li et al. 2015) such as using beetles larvae maceration to feed around and remove the seeds. Insect species that exhibit innate biological compatibility with target pre-consumer organic wastes, and/or possess an exploitable functional service, can then be further improved via artificial selection (targeted breeding). In this way, specific insect species with distinct traits (i.e., physiological, microbial, behavioral) can be bred to function as the "ideal insect bioconverters" for a target waste stream.

Here, we consider candidate "ideal insect bioconverters," as those that possess as many of the traits listed in Table 1 as possible. Certainly, no incipient bioconverter species or population will possess all these traits initially, but a strain of insects
Table 1 Traits of ideal insect bioconverters

\begin{tabular}{|c|c|c|}
\hline \multirow[t]{7}{*}{ Biology } & \multirow[t]{5}{*}{ Physical } & High consumption rate \\
\hline & & Rapid development \\
\hline & & Large bodied (at harvest) \\
\hline & & Fecund \\
\hline & & Moisture and heat tolerant \\
\hline & \multirow[t]{2}{*}{ Ecological } & Polyphagous \\
\hline & & Communal \\
\hline \multirow[t]{8}{*}{ Rearing } & \multirow[t]{6}{*}{ Maintenance } & Operationally scalable \\
\hline & & Large colonies easy to maintain \\
\hline & & Easy to rear/cultivate \\
\hline & & Multiple stages feed on same diet \\
\hline & & Low/negligible susceptibility to diseases \\
\hline & & Low/negligible susceptibility to parasites \\
\hline & \multirow[t]{2}{*}{ Processing } & Life stages easy to separate \\
\hline & & $\begin{array}{l}\text { Self-removing behavior and/or } \\
\text { easily extracted }\end{array}$ \\
\hline \multirow[t]{6}{*}{ Usage } & \multirow{3}{*}{$\begin{array}{c}\text { Functional } \\
\text { service }\end{array}$} & Mechanical separation \\
\hline & & Toxin sequestration \\
\hline & & Consumes lignin \\
\hline & \multirow{3}{*}{$\begin{array}{l}\text { Active } \\
\text { compounds }\end{array}$} & High nutritional value \\
\hline & & $\begin{array}{l}\text { Rich multiple valuable compounds } \\
\text { (lipid, protein, chitin) }\end{array}$ \\
\hline & & Frass is of value \\
\hline \multirow[t]{6}{*}{ Safety } & \multirow[t]{5}{*}{ Human } & Hypoallergenic \\
\hline & & Easy to handle/docile \\
\hline & & Not prone to escape \\
\hline & & Does not sting/bite \\
\hline & & Does not transmit diseases to humans \\
\hline & Environmental & Non-invasive \\
\hline
\end{tabular}

subjected to targeted breeding may ultimately gain a unique potential for bioconversion of a particular waste stream at a large scale (Jensen et al. 2017). Considering the sizeable literature on insects undergoing rapid adaptation in nature, including adapting to new foods, (Carroll and Loye 2012; Carroll et al. 1998) ecological communities, (Strauss et al. 2006) pesticides, (Tabashnik 1994) and experimental evolution in the laboratory, (Beldade et al. 2005) it is reasonable to predict targeted breeding programs could rather rapidly and cost-effectively yield new and significantly improved bioconverters in manageable and economically practicable time frames.

\subsection{Insect species currently used as bioconverters}

At present, only a handful of insect species are used for bioconversion of organic wastes, with the most represented species being (Anankware et al. 2015; Van Huis et al. 2013) crickets, locusts Locusta migratoria, black soldier flies Hermetia illucens, green bottle flies Lucilia sericata, and several mealworm species, including the yellow mealworms 
Tenebrio molitor (see Table 2 for an extended list). Research on the growth performance and feeding conversion of these species suggests they alone are not sufficient to fully capitalize on the high diversity of unique organic wastes available for bioconversion. For instance, the most utilized bioconverter, the black soldier fly (Fig. 2), has a well-documented capacity to break down wastes, (Surendra et al. 2016; Barry 2004; Diener et al. 2009; Nguyen et al. 2015) which evolved in the context of feeding on nutrient-rich decaying biomass. However, studies have shown that black soldier flies are only marginally suited for bioconversion of low-nutrient fruit and vegetable pulps (Smetana et al. 2016). Similarly, research has shown markedly different performance in feeding efficiency and growth rates of three mealworm species, which were reared on four different organic waste diets of variable starch and protein composition (Van Broekhoven et al. 2015). The authors concluded that certain diets may be unsuitable for mealworms due to a lack of essential nutrients, and that mealworms reared on high-starch diets (49.8\% starch; $10.7 \%$ crude protein; $1.8 \%$ crude fat) had the lowest growth and waste conversion rates.

\subsection{The role of gut symbionts}

An important consideration in the pursuit of ideal insect bioconverters is the prospect of incorporating modern invertebrate microbiome research into targeted breeding programs of ideal insect bioconverters. Studies have shown that invertebrate symbiont interactions are hyper-diverse and critical in facilitating host exploitation of food resources, (Gibson and Hunter 2010; Ceja-Navarro et al. 2015) and that gut symbiont community structures correlate with the chemical composition of the host's food source (Engel and Moran 2013). For instance, in multiple insect species [including fruit flies (Drosophila spp.), Indianmeal moth (Plodia interpunctella), gypsy moth (Lymantria dispar), and German cockroach (Blattella germanica)], there is a relationship between body protein content and the host's bacterial diversity (Chandler et al. 2011; Montagna et al. 2016; Mason and Raffa 2014; Pérez-Cobas et al. 2015). While insects are generally considered to be less symbiont rich compared to other animals, such as vertebrates, polyphagous insect species have higher symbiont species richness compared to specialists (Gibson and Hunter 2010). One hypothesis possibly explaining the difference in gut symbiont diversity suggests diverse diets do not require particular symbionts, and therefore, polyphagous hosts benefit from the diversified metabolic capabilities provided by a wider array of symbionts (Montagna et al. 2016). From the perspective of developing ideal bioconverters, monitoring the microbial diversity developing within insect-to-waste pairings will be of high value in the pursuit of optimizing insects as bioconverters.

Table 2 Insect bioconverters and their corresponding bioconversion outputs

\begin{tabular}{|c|c|c|c|c|}
\hline Species & Organic waste & Country & Bioconversion output & Reference \\
\hline \multirow[t]{14}{*}{ Black soldier fly (Hermetia illucens) } & \multicolumn{4}{|l|}{ Rice straw $(30 \%)$} \\
\hline & Restaurant waste $(70 \%)$ & China & Biofuel & 53 \\
\hline & Rice straw & Indonesia & Biomass & 54 \\
\hline & Coffee pulp, husk & El Salvador, Indonesia & Biomass, fertilizer & 55,56 \\
\hline & $\begin{array}{l}\text { Reject material from pears, banana, } \\
\text { and cucumber }(5: 3: 2)\end{array}$ & Sweden & Biomass & 57 \\
\hline & Spent distiller grain & USA & Biomass & 62 \\
\hline & Fruits and vegetables & Canada & Biomass & 31 \\
\hline & Corn stover & China & Biofuel, soil amendment & 59 \\
\hline & Corncob & China & Biofuel & 28 \\
\hline & Sorghum & USA & Biomass & 60 \\
\hline & Cowpea & USA & Biomass & 60 \\
\hline & Cassava peel & Indonesia & Biomass & 61 \\
\hline & $\begin{array}{l}\text { Vegetable trimmings, spent coffee } \\
\text { grounds, and tea leaves }\end{array}$ & USA, Hong Kong & Biomass & 62 \\
\hline & Vegetables, peels of yam, cassava, plantain & Ghana & Biomass & 63 \\
\hline \multirow[t]{2}{*}{ Housefly (Musca domestica) } & \multicolumn{4}{|l|}{ Restaurant waste $(70 \%)$} \\
\hline & Whole plant corn silage, sawdust (30\%) & China & Biomass, biofuel, fertilizer & 64 \\
\hline Codling moth (Cydia pomonella) & Starch and cheese wastewater sludge & Canada & Biomass & 65 \\
\hline $\begin{array}{l}\text { Cambodian field crickets } \\
\quad \text { (Teleogryllus testaceus) }\end{array}$ & $\begin{array}{l}\text { Cassava plant tops, spent grain, mung } \\
\text { bean sprout waste, field weeds }\end{array}$ & Cambodia & Biomass & 66 \\
\hline \multirow[t]{2}{*}{ Yellow mealworm (Tenebrio molitor) } & Wheat straw, bruised cabbage leaves & China & Biomass & 67 \\
\hline & Corn stover & China & Biofuel & 59 \\
\hline
\end{tabular}




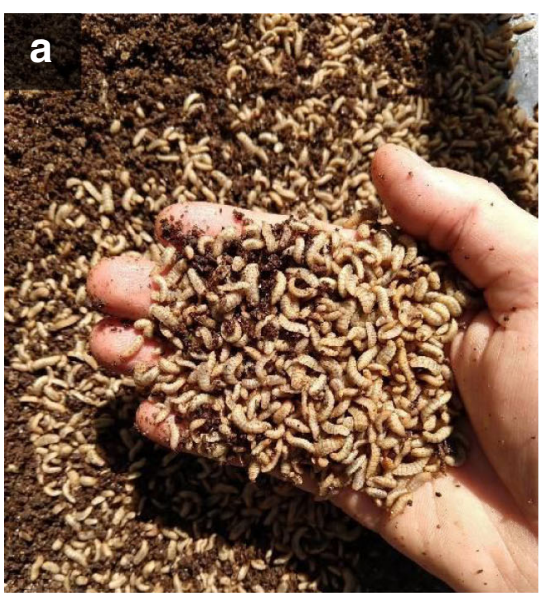

Fig. 2 Different life stages of black soldier flies (Hermetia illucens) in bioconversion systems. Many insect bioconverters require different rearing parameters throughout their life cycle. a Black soldier fly larvae growing in almond hulls. Key requirements for this life stage include high

Experiments discerning how direct manipulations of a host's gut symbiont community alter host performance and efficiency in bioconverting biomass may yield valuable insight into the bioconversion potential of particular interactions (Scheuring and Yu 2012; Mueller and Sachs 2015). Several strategies may be deployed for direct manipulation of gut microbe-host interactions. First, facultative gut symbionts can be transferred horizontally between target bioconverters, to aid in modulating immunity or accessibility of essential amino acids (Łukasik et al. 2015). Second, organic wastes may be inoculated with beneficial companion bacteria. This practice is already used in part to induce oviposition in black soldier fly, where bioconverted substrate is added to fresh media to make an attractant for gravid females to lay eggs (Nakamura et al. 2016). Likewise, agar inoculated with the bacteria isolated from black soldier fly leads to higher rates of female oviposition, (Zheng et al. 2013). suggesting volatiles emitted from the microbiota of conspecifics mediate oviposition. While these techniques are not a direct manipulation of the gut symbionts per se, cues from the bacteria inform female flies of substrates with microbial communities favorable for larval growth. For example, when chicken manure is inoculated with black soldier fly companion bacteria, the adult body length of flies increases, while the development time from hatching to $90 \%$ reaching the prepupual stage is reduced by $\sim 5$ days ( 29.00 \pm 1.00 days vs. $34.33 \pm 3.51$ days), (Yu et al. 2011) both valuable improvements for insect bioconversion enterprises. Finally, as interest in bioconversion advances, a bioconverter symbiont community may be manipulated by inclusion of genetically modified symbionts added for custom-made bioconversion applications. To our knowledge, this final strategy has not yet been used in insects used as bioconverters of pre-consumer organic wastes. However, the strategy has been used to reduce transmission of diseases by biting insects, (Taracena et al. 2015) as well as to introduce transgenic gut symbionts to an entire termite colony from only a few initially inoculated individuals

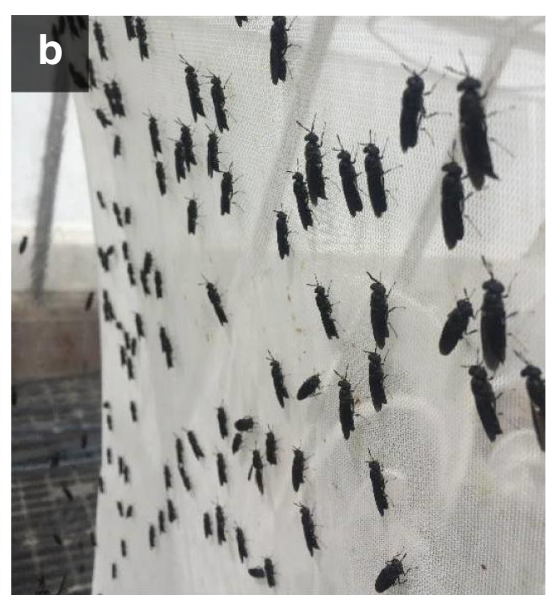

moisture content, evacuation of gasses (aeration), limited light, and access to food. b Adult black soldier fly in caged enclosure. Key requirements for this life stage include sufficient light for mating displays, ample flying space for aerial copulation, and egg traps with oviposition stimulant

(Husseneder and Grace 2005). One could imagine how engineered microbes, perhaps capable of synthesizing more complete amino acid profiles, may assist and add value to insect's bioconverting nutrient-deficient pre-consumer wastes, such as almond hulls or tomato pomace. In summary, insectbased bioconversion of pre-consumer organic wastes will benefit from comprehensive strategies, those using microbial surveillance and direct manipulations, that incorporate both the health and composition of insect-symbiont relationships. Furthermore, knowledge derived from livestock breeding and other disciplines will be of tremendous value in this effort.

\subsection{Bioconversion outputs}

A detailed review by Makkar et al. cites numerous studies of the chemical constituents of insect meals derived from various pre-consumer organic wastes, and lists the insect meals' nutritional value when consumed by different animal species (Makkar et al. 2014). In addition, many life cycle assessments and protocols have been developed for these insect species for use as animal feed or secondary products (i.e., pharmaceuticals, lubricants, biodiesels) (Ortiz et al. 2016; Jensen et al. 2017; Anankware et al. 2015). Table 2 includes a compiled review of organic wastes and bioconversion outputs for the most commonly cited bioconverting species, as well as other less commonly cited insects.

\section{Substantive gains from artificial selection and discovery}

\subsection{Mining insect diversity}

Insects are the most hyper-diverse grouping of animals on the planet (Zhang 2011). Recent estimates put the number of 
described species at over 1 million (Stork 2018). Half of this diversity is captured within the groups containing the most commonly cited bioconverting species (beetles: 386,500 ; flies: 155,477; butterflies and moths: 157,338; grasshoppers: 23,855; cockroaches: 7314). Intuitively, most species will not be enlisted as bioconverters, but use of insects for bioconversion of waste material is a rapidly growing industry, and interest in finding new applications for waste valorization and subsequent sources of sustainable proteins warrant experimentation into new insect-to-waste pairings (Rumpold et al. 2017).

Taking into account the remarkable diversity of insects capable in providing bioconversion services versus the dearth of species conventionally used, (Yen and Van Itterbeeck 2016) further investigation is warranted into research of additional insect species to assess their potential performance as bioconverters. Such future research will likely elucidate not only additional candidate species for waste bioconversion, but it may lead to identification of exploitable enzymes and microbial symbionts facilitating organic waste bioconversion, (Rumpold et al. 2017) yielding unforeseen economic and societal benefits. (Bull 2004) An obvious concern is the rapid decline in insect biodiversity (Sánchez-Bayo and Wyckhuys 2019). That is, specialized insect species with unique adaptations to certain host materials that resemble certain preconsumer organic wastes may be harder to identify, if the current decline in insect biodiversity continues.

\subsection{Breeding program design}

Table 1 provides a list of the many traits that could be used in targeted selection, and priority in ranking of these traits is defined by the breeding program's goal and method of selection. One of the first considerations when beginning a targeted breeding program for a specific insect bioconverter is to standardize rearing conditions (Dyck et al. 2006; Whitman 2009; Meyers and Bull 2002). This ensures that the phenotypes being quantified, and resulting selection decisions, are the result of genetic difference between individuals and not the environment. Consistency is critical for the program to be reliable and effective, as genetic variation can be masked by environmental influences (McCarty 2017; Moczek 2010). Moreover, the environment in which breeding trials are performed should be similar to the environment where large-scale bioconversion will take place (Almekinders and Elings 2001). For example, in black solider fly bioconversion, a local Chinese strain outperformed foreign strains in both their bioconversion and weight gain efficiency, (Zhou et al. 2013) suggesting their adaptations to the local environment impacted bioconversion performance. Similarly, bioconverters express different growth rates and nutritional quality depending on the food waste (Van Broekhoven et al. 2015; Manurung et al. 2016; Leong et al. 2015). Drawing on practices used in livestock and aquaculture, several breeding program designs may be used to breed insects for bioconversion, including (1) the tandem selection method, (2) independent culling levels, and (3) index selection (Bourdon and Bourbon 2000). Each method is briefly described below. The relative performance of each method depends on selection intensity, number of traits under selection, the traits relative importance, heritability, and a trait genetic correlation to other desirable traits (Sen and Robertson 1964).

The tandem method selects for one trait per generation (Fig. 3a) and alternates between one of two (or more) traits each generation. However, selection for a particular trait may continue for several generations before switching to the other trait (Lush 1943). While simple and cost effective, this method is considered inefficient due to (1) selection pressure is relaxed when moving to subsequent traits and (2) less heritable or economically valuable traits may undergo selection for too few (or too many) generations (Hazel and Lush 1942). However, in some contexts, tandem selection may be useful for traits with high heritability (Brim and Burton 1979). Independent culling selection selects for two or more traits in each generation, and only individuals meeting or exceeding a measured threshold are permitted to breed and contribute to the subsequent generation. Index selection calculates the estimated breeding value of individuals, pairing couples with high predictive value.

Breeding programs using the independent culling method selects for 2-3 traits at once, setting minimum limits for the phenotype of each trait (Fig. 3b). Individuals falling below these limits are culled from the breeding population, while those reaching or exceeding certain thresholds are mated. This is repeated for each cycle of breeding. Figure $3 \mathrm{~b}$ shows selection for two traits: "days to pupation" ( $x$-axis) and "larval weight" ( $y$-axis) for black soldier fly. Note that individuals with high-performing phenotypes for one trait may be culled if not exceeding the threshold for the second trait. Large numbers of individuals are culled, when minimum thresholds are set too high. This should be avoided, as too strong a selection intensity will deplete the genetic diversity of the breeding stock and slow improvement of target phenotypes. This is not unlike challenges found in conservation biology, which implements the " 500 " rule, a theoretical minimum viable population size, which balances allelic drift and mutation (Franklin 1980). Later reviews on minimum viable populations have placed suggested populations at approximately 5000 individuals to be sufficient in preventing the loss of quantitative genetic variation (Frankham 1995). For insect breeders, this is easily obtainable by leveraging the prolific reproduction of insects to maintaining large colonies during selection. For example, black soldier flies are very fecund, with an average of 998 eggs per mass (Booth and Sheppard 1984). Therefore, larval colonies with populations of many hundreds of thousands may be subjected to selection pressures leading to a final breeding colony of $\sim 10,000$ individuals. In addition, black soldier flies have relatively large genomes compared 
a

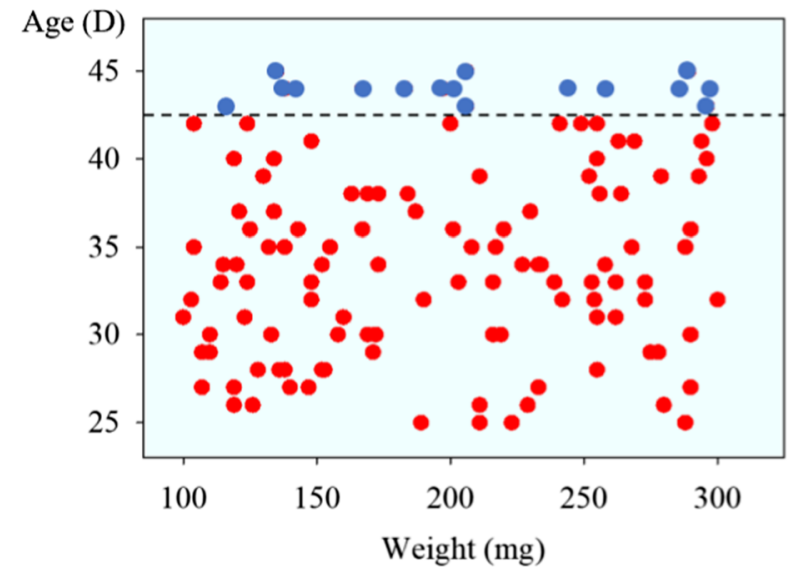

Fig. 3 Example of two methods for breeding based on selecting for specific quantitative traits. Theoretical data illustrating how tandem selection (a) or independent culling selection (b) can be used to eliminate individuals below one or two thresholds (dotted line(s)). Some individuals (blue dots) are selected for further breeding, while

to other flies, (Vicoso and Bachtrog 2015) suggesting ample genetic material for selection (Oliver et al. 2007). This point is also exemplified in red flour beetles (Tribolium castaneum, a relative of mealworms), which exhibited little decrease in genetic gain per generation when selected for pupal weight over 120 generations, eventually accumulating a weight increase 17 standard deviation units from the source population's mean (Enfield 1980). By leveraging these aspects of insect biology, breeders may find independent culling a relatively easy and productive method to implement compared to other methods like tandem selection and index selection (below).

The index selection method selects for multiple traits each generation, and unlike the other two methods, can be used effectively with more than three traits. Index selection incorporates estimated breeding values (EBVs) for multiple traits into a single index of values that are used in making selection decisions. EBVs are multiple regression predictors of an offspring's performance and are calculated from observations of an individual, or its relatives. Calculating a selection index requires information on genetic correlation, heritability of traits, and the economic value of the phenotype (Hazel 1943). Unfortunately, these are not well defined for insect bioconverters as the following knowledge is largely missing: (1) correlation of traits and trait heritability need to be resolved for bioconverter species and (2) uncertainty of regulations and regional markets affect economic values of the phenotypes (Makkar et al. 2014). However in theory, index selection is never less efficient than independent culling,(Hazel and Lush 1942) though in some cases it may be no more efficient. Consequently, it is the most used selection system in animal and plant breeding (Bourdon and Bourbon b Independent culling selection

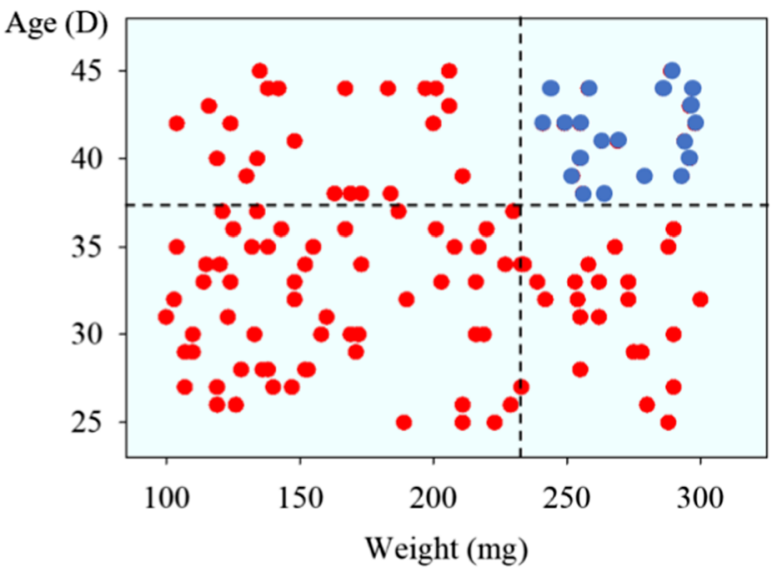

others (red dots) are culled. An advantage of independent culling is that the selection pressure is not relaxed since multiple traits may be targeted at once. However, multiple thresholds may eliminate more individuals from subsequent pools of a breeding population; therefore, lower thresholds are typically maintained

2000; Campo and Villanueva 1987). For this to be applied to insect bioconverters, meaningful phenotypes need to be measured using standardized data collection methods, and economic weight needs to be placed on each phenotype. Finally, logistical frameworks are needed for the husbandry of numerous insect crosses and their subsequent progeny.

\subsection{Adaptive phenotypic plasticity}

Phenotypic plasticity is the deterministic genetic expression of observable traits (phenotypes) resulting from an organism gene (genotype) in response to its environment (Whitman 2009). The same genotype may produce different phenotypes under different unique environmental conditions. Phenotypic plasticity includes changes to an individual's physiology, morphology, behavior, or life history (Moczek 2010). These changes counter environmental variation to alter fitness either within or between generations (Whitman 2009; Meyers and Bull 2002). Moreover, phenotypic plasticity is ubiquitous across living sexually reproducing organisms and thought to be commonly adaptive in insects (Whitman 2009).

Quantitative genetic models treat an organism's phenotype $(\mathrm{P})$ as the product of its genetics and the environment $(\mathrm{G} \times \mathrm{E})$ (Fig. 4), and genotype-by-environment interactions are well studied in insects (Van Broekhoven et al. 2015; Moczek 2010; Gobbi et al. 2013). Likewise, the quantifying genotype by environment are of great interest to insect breeders, because unlike traits emerging from genetic evolution, trait variation due to phenotypic plasticity is not heritable, though it maximizes fitness in variable environments. This is important for 


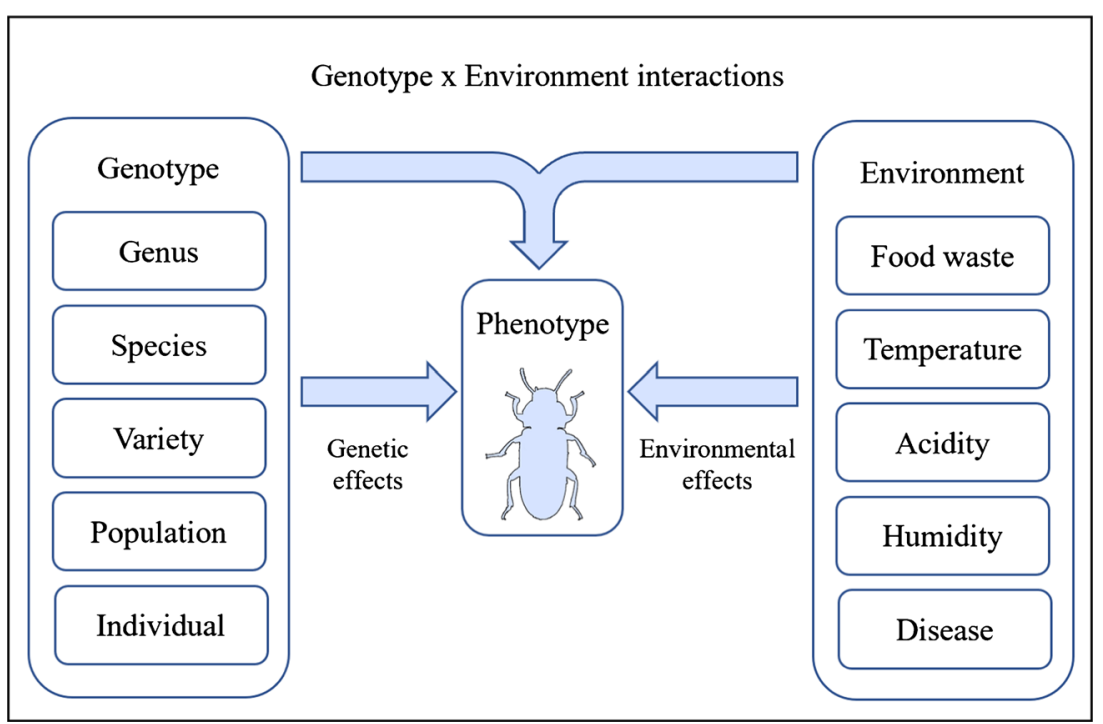

Fig. 4 Conceptual model of factors responsible for the phenotypic traits of an insect bioconverter. An insect individual's phenotype is a product of its genetics in response to environmental conditions. Change in either the genetics of the organism (genotype) or the environmental conditions the

insects used in bioconversion, because the transition from ancestral food sources to novel diets of pre-consumer organic food waste may not necessarily be accompanied with the genes conferring high performance for the new waste. Insects' plastic responses allow them to bridge the gaps temporally, while the adaptive genes for the novel diets of preconsumer organic waste accumulate in the population. Thus, the ability to convert a new food resource increase may increase over generations, but often at the expense of adaptation to the ancestral diet (Fig. 5). Some examples of insect adaptive phenotypic plasticity in response to food quality include black soldier fly larvae adjusting energy budgets to prioritize growth and metabolism in response to a diminishing food source (Manurung et al. 2016). Another example is grasshoppers (Schistocerca americana) increasing the relative number of sensory hairs (sensilla) when fed diets supplemented with volatile compounds (Bernays and Chapman 1998). Deterministic expression of traits in response to the environment result in trade-offs during development but diversify populations' available evolutionary trajectories (Moczek 2010; Fry 1990). Thus, the increased allocation of resources for growth and metabolism in the black soldier flies comes at the cost of self-maintenance, such as supporting a robust immune defense (DeBlock and Stoks 2008) or increased reproduction (Chippindale et al. 2004).

Adaptation via phenotypic plasticity plays a major role in insect development and evolution, and it should be considered an integral component of insect-based bioconversion programs (Jensen et al. 2017; De Jong and Bijma 2002). Moreover, insect breeders should assess a population's response to environmental conditions to better select stock for individual's experiences alters which phenotypes are expressed. Phenotypic expression of traits may include size, fecundity, behavior, lifespan, susceptibility to disease, and fat content

different environments or for robust tolerance to environmental variation. Phenotypic plasticity in insects used for bioconversion needs to be carefully considered for the following reasons: (1) to determine population variation in response to environments (e.g., novel food wastes, biotic and abiotic factors); (2) to leverage parental bio-response and offspring imprinting to identify and amplify better adapted populations; and (3) to develop monitoring programs as a means of quality

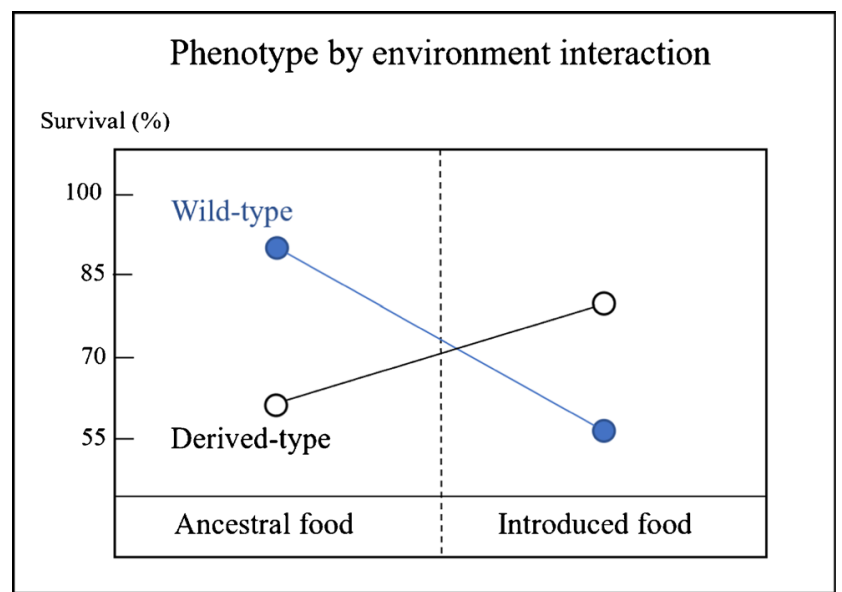

Fig. 5 Change in survival of insect populations in response to selection in populations that shifted to an introduced host. Survival of two different populations of the same species of insects. In nature, the wild-type feeds on an ancestral food source, while the derived-type feeds on an introduced plant species. Although only a few decades have passed since the plants' introduction, enough response to selection has occurred such that the phenotype of the insects (survival) differs depending if the two populations are fed either their ancestral or the introduced food. This figure is adapted from results of Carroll et al. 1998) 
control to assess if variation in fitness is due to plasticity, or genetic gains as a result of the breeding program.

\subsection{How to monitor and quantify adaptive phenotypic plasticity}

Phenotypic plasticity is measured using "variance partitioning," quantified by the deviation of traits from the mean, for genotypes across different environments (Pigliucci 2001). Experimental designs compare individual responses to controlled environmental treatments, using individuals of close relatedness (i.e., full siblings, clones, back-crossings), thereby reducing observed variance due to genetics (Carroll et al. 1998; Schneider et al. 2011). Results are graphically presented as the "reaction norms," which plot plastic responses (e.g., behavior, survival, fecundity, consumption rate) across multiple environmental treatments (Stearns and Koella 1986; Via et al. 1995). For example, Fig. 5 illustrates variable adaptation of two populations of insects reared in two different environments, in this case diets of either a native or introduced plant species. Here, wild-type insects are far more likely to survive on the native host plant compared to the introduced host species. Conversely, derived-type insects, adapted to and feeding on the introduced plant species, perform poorly on their ancestral host. The transition from wild-type to derived-type appears to have naturally occurring over only a few decades (Carroll et al. 1998). This method of reciprocal rearing therefore may be used to elucidate differences in performance for environments these insects encounter. Similar reciprocal rearing experiments can be used to monitor and quantify the gradual adaptation from breeding of candidate insect bioconverters to a novel target waste stream (Badenhorst 2017; Brits 2017). For example, artificial selection for increased thorax length in fruit fly, and thus larger body size, has been shown to correlate with a drop in larval survival at higher larval densities (Santos et al. 1994). Reciprocal rearing for a genotype's response across multiple environments (i.e., stocking densities) will inform how artificial breeding may be shifting optimum rearing parameters of bioconversion operations.

Interestingly, breeders may want to target insect's plasticity itself, whereby treating the robustness or plastic response to environmental conditions becomes part of the breeding program's goals (De Jong and Bijma 2002). Some pre-consumer wastes are relatively homogenous and may be bioconverted under highly controlled conditions, thus permitting a more robust phenotype (less plastic) to be sufficient for valorization. However, many wastes undergo a succession of microbial colonization when bioconverted by insects, leading to wide shifts in the temperature and moisture content of the substrates as bacteria and fungi reproduce and metabolize nutrients (Ushakova et al. 2018). Additionally, some models for insect bioconversion have breeding and egg production facilities far from the location bioconversion actually occurs, necessitating insects to tolerate not only variable environmental conditions, such as temperature and humidity, but also differences in regional crop varieties, which may differ in nutrient quality (Palma et al. 2018). Viewed in this way, the plasticity across environment itself may be treated a component within the estimated breeding values used in index selection (Kirkpatrick and Bataillon 1999). In this way, breeding program objectives may be set to maximize phenotypic responses across environments. For example, consider the combined selection for both larger body size and fat content, but under conditions of variable stocking densities. Lower stocking densities permit les per capita competition for resources, and thus a larger body size with more fat content. Here, the increase in fat is presumably the result of larger body size, which comes from the greater availability to food at lower stocking density (i.e., scaling effects). However, from the breeder's perspective, greater food availability should preferably result in insects of the same size, but with their greater fat content being the result of genetic gains rather than environmentally determined plasticity. As previously mentioned, some insects artificially selected for increased larger body also experience a drop in larval survival at higher stocking densities (Santos et al. 1994). Thus, a breeder may choose to maximize fat content across environments (stocking densities), thereby increasing the output of fat genetically regardless of environmental influences pre-determining size.

Assessing phenotypic plasticity in large-scale breeding and bioconversion operations may be economically prohibitive; therefore, indirect methods should be used. One approach for capitalizing on the adaptive nature of individual plasticity is "following the bio-response" of gravid females (i.e., oviposition preference). For example, vegetable leaf miner females (Liriomyza sativae) collected on cowpea and tomato show no preference for oviposition on either host when presented each host singly in 24-h trials in alternating order, and average larval performance (pupal weight) does not differ between hosts (Via 1986). However, individual performance of larvae relative to siblings' positively regresses on the decision of the mother. Meaning, mothers' preference at the individual level produces offspring better suited for that host, even if the mean oviposition preference suggests no difference. Large-scale breeding and bioconversion operations allowing gravid females to self-select may pose a cost-efficient method for capitalizing on adaptive phenotypic plasticity. Furthermore, insects' natal experience has been found to influence later generations' preference for suitable environments. For example, that gravid flies unable to find familiar host plants will oviposit on novel hosts and produce offspring that imprint on the new host that seek these new plants over the ancestral host as adults (Feder et al. 1994). This cycle of gravid female bioresponse and natal experience imprinting happens passively in many insect colonies, allowing the population to adapt to their artificial environment (Zhou et al. 2013; Badenhorst 
2017; Schutze et al. 2015; Meats et al. 2004). To develop stock for multiple food wastes or stock with robust tolerance to variation, we suggest active monitoring and experimentation on colonies' phenotypic plasticity over time.

\section{Conclusion}

Governmental agencies across Europe, North America, and elsewhere are increasingly advocating zero-waste programs, colloquially referred to as circular or bio-economies (Commission, E. U 2014; Commission, E 2012). A primary challenge in developing such zero-waste programs centers on waste disposal and re-use (i.e., recovery of nutrients and valuable compounds) (Bernal and Grand 2017). Conventional sustainable practices, such as composting and biorefining, should include insect bioconverters as mechanisms for managing large quantities of organic pre-consumer food waste (Oonincx and De Boer 2012). Many countries worldwide have active research programs into insects as bioconverters and private companies are developing large-scale facilities. Optimization of insects as bioconverters will greatly benefit from ecologically and biologically informed insect-to-waste pairings and the subsequent improvement on insect strains through breeding. Such ventures will drive novel research and the development of new economic opportunities. Several breeding methods exist for achieving those breeding goals, with tandem and independent culling offering quick and easy improvement of limited traits. In the future, more sophisticated and capital-intensive breeding programs will overcome nascent technical and biological obstacles inhibiting breeding, likely leading to the development of selection indices and genome-based selection. Ultimately, visions of a zero-waste future will include insects as waste bioconverters at an industrial scale, with the societal dividends of a plentiful source of proteins for animal feed, as well as lucrative downstream secondary products.

Funding information This chapter was written based on partial funding from the United States Department of Agriculture's (USDA) program for Western Sustainable Agriculture Research and Education (WSARE) (sub-award: 200592-446), as well as partial funding from the U.S. Department of Agriculture's (USDA) Agricultural Marketing Service through grant 18-00001-028-SC. Its contents are solely the responsibility of the authors and do not necessarily represent the official views of the USDA.

\section{Compliance with ethical standards}

Conflict of interest The authors declare that they have no conflict of interest.

Open Access This article is distributed under the terms of the Creative Commons Attribution 4.0 International License (http:// creativecommons.org/licenses/by/4.0/), which permits unrestricted use, distribution, and reproduction in any medium, provided you give appropriate credit to the original author(s) and the source, provide a link to the Creative Commons license, and indicate if changes were made.

\section{References}

Almekinders CJM, Elings A (2001) Collaboration of farmers and breeders: participatory crop improvement in perspective. Euphytica 122:425-438 Google Scholar

Anankware PJ, Fening KO, Osekre E, Obeng-Ofori D (2015) Insects as food and feed: a review. Int J Agric Res Rev 3:143-151 Google Scholar

Badenhorst R (2017) Genetic diversity in a commercial black soldier fly, Hermetia illucens (Diptera: Stratiomydiae), population. Stellenbosch University, Stellenbosch Google Scholar

Barry, T. Evaluation of the economic, social, and biological feasibility of bioconverting food wastes with the black soldier fly (Hermetia illucens). (2004). Google Scholar

Beldade P, Brakefield PM, Long AD (2005) Generating phenotypic variation: prospects from "evo-devo" research on Bicyclus anynana wing patterns. Evol Dev 7:101-107. https://doi.org/10.1111/j. 1525-142X.2005.05011.x PubMed Google Scholar

Bernal M, Grand P (2017) Challenges in waste management in agroecosystems. Front Sustain Food Syst 1:1. https://doi.org/10. 3389/fsufs.2017.00001 Google Scholar

Bernays EA, Chapman RF (1998) Phenotypic plasticity in numbers of antennal chemoreceptors in a grasshopper: effects of food. J Comp Physiol A 183:69-76. https://doi.org/10.1007/ s003590050235GoogleScholar

Booth DC, Sheppard C (1984) Oviposition of the black soldier fly, Hermetia illucens (Diptera: Stratiomyidae): eggs, masses, timing, and site characteristics. Environ Entomol 13:421-423. https://doi. org/10.1093/ee/13.2.421 GoogleScholar

Bourdon RM, Bourbon RM (2000) Understanding animal breeding, vol 2. Prentice Hall, Upper Saddle River Google Scholar

Brar SK, Dhillon GS, Soccol CR (2013) Biotransformation of waste biomass into high value biochemicals. Springer. https://doi.org/10. 1007/978-1-4614-8005-1 Google Scholar

Brim CA, Burton JW (1979) Recurrent selection in soybeans. II. Selection for increased percent protein in seeds 1. Crop Sci 19: 494-498. https://doi.org/10.2135/cropsci 1979. 0011183x001900040016x Google Scholar

Brits D (2017) Improving feeding efficiencies of black soldier fly larvae, Hermetia illucens (L., 1758) (Diptera: Stratiomyidae: Hermetiinae) through manipulation of feeding conditions for industrial mass rearing. Stellenbosch University Google Scholar

Bull AT (2004) Microbial diversity and bioprospecting. ASM press. https://oi.org/10.1128/9781555817770 Google Scholar

(2012) California Food Processing Industry Organic Residue Assessment, CEC-500-2013-100; California Biomass Collaborative: Davis, CA

Campo JL, Villanueva B (1987) Experimental comparison of restricted selection index and restricted independent culling levels in Tribolium castaneum. Genome 29:91-96. https://doi.org/10.1139/ g87-016 Google Scholar

Carroll SP, Loye JE (2012) Soapberry bug (Hemiptera: Rhopalidae: Serinethinae) native and introduced host plants: biogeographic background of anthropogenic evolution. Ann Entomol Soc Am 105:671-684. https://doi.org/10.1603/AN11173GoogleScholar

Carroll SP, Klassen SP, Dingle H (1998) Rapidly evolving adaptations to host ecology and nutrition in the soapberry bug. Evol Ecol 12:955968. https://doi.org/10.1023/A:1006568206413 Google Scholar

Ceja-Navarro JA, Vega FE, Karaoz U, Hao Z, Jenkins S, Lim HC, Kosina P, Infante F, Northen TR, Brodie EL (2015) Gut microbiota mediate caffeine detoxification in the primary insect pest of coffee. Nat 
Commun 6:7618. https://doi.org/10.1038/ncomms8618 Pub Med Google Scholar

Chandler JA, Lang JM, Bhatnagar S, Eisen JA, Kopp A (2011) Bacterial communities of diverse Drosophila species: ecological context of a host-microbe model system. PLoS Genet 7:e1002272. https://doi. org/10.1371/journal.pgen.1002272 PubMed Google Scholar

Chippindale AK, Leroi AM, Kim SB, Rose MR (2004) Phenotypic plasticity and selection in Drosophila life-history evolution. I. Nutrition and the cost of reproduction. In: Methuselah flies: a case study in the evolution of aging. World Scientific, pp 122-144. https://doi.org/10. 1046/j.1420-9101.1993.6020171.x Google Scholar

Čičková H, Newton GL, Lacy RC, Kozánek M (2015) The use of fly larvae for organic waste treatment. Waste Manag 35:68-80. https:// doi.org/10.1016/j.wasman.2014.09.026PubMed

Codex Alimentarius Commission (2014) General principles of food hygiene. CAC/RCP 1-1969. World Health Organ, Geneva Switz, pp $1-31$

Colby, S. L. \& Ortman, J. M. Projections of the size and composition of the US population: 2014 to 2060: population estimates and projections. (2017). Google Scholar

Commission, E (2012) Innovating for sustainable growth: a bioeconomy for Europe. Ind Biotechnol 8:57-61. https://doi.org/10.1089/ind. 2012.1508 Google Scholar

Commission, E. U (2014) Towards a circular economy: a zero waste programme for Europe. COM 2014 398. https://doi.org/10.24264/ icams-2018.xi.4

De Jong G, Bijma P (2002) Selection and phenotypic plasticity in evolutionary biology and animal breeding. Livest Prod Sci 78:195-214. https://doi.org/10.1016/s0301-6226(02)00096-9 Google Scholar

DeBlock M, Stoks R (2008) Short-term larval food stress and associated compensatory growth reduce adult immune function in a damselfly. Ecol Entomol 33:796-801. https://doi.org/10.1111/j.1365-2311. 2008.01024.xGoogleScholar

Diener S, Zurbrügg C, Tockner K (2009) Conversion of organic material by black soldier fly larvae: establishing optimal feeding rates. Waste Manag Res 27:603-610.https://doi.org/10.1177/ 0734242X09103838PubMedGoogleScholar

Diener S, Solano NMS, Gutiérrez FR, Zurbrügg C, Tockner K (2011) Biological treatment of municipal organic waste using black soldier fly larvae. Waste Biomass Valorization 2:357-363. https://doi.org/ 10.1016/j.wasman.2014.09.026PubMed

Dyck VA, Hendrichs J, Robinson AS (2006) Sterile insect technique: principles and practice in area-wide integrated pest management. Springer Google Scholar

Endler JA (1986) Natural selection in the wild. Princeton University Press Google Scholar

Enfield FD (1980) Long term effects of selection: the limits to response. In: Robertson A (ed) Selection experiments in laboratory and domestic animals: proceedings of a symposium held at Harrogate, UK, on 21st-22nd July 1979. Commonwealth Agricultural Bureau, Slough Google Scholar

Engel P, Moran NA (2013) The gut microbiota of insects-diversity in structure and function. FEMS Microbiol Rev 37:699-735. https:// doi.org/10.1111/1574-6976.12025 PubMed Google Scholar

Eriksson M, Strid I, Hansson P-A (2015) Carbon footprint of food waste management options in the waste hierarchy - a Swedish case study. J Clean Prod 93:115-125. https://doi.org/10.1016/j.jclepro.2015.01. 026GoogleScholar

Feder JL, Opp SB, Wlazlo B, Reynolds K, Go W, Spisak S (1994) Host fidelity is an effective premating barrier between sympatric races of the apple maggot fly. Proc Natl Acad Sci 91:7990-7994. https://doi. org/10.1073/pnas.91.17.7990 PubMed Google Scholar

Foley JA, Ramankutty N, Brauman KA, Cassidy ES, Gerber JS, Johnston M, Mueller ND, O'Connell C, Ray DK, West PC, Balzer C, Bennett EM, Carpenter SR, Hill J, Monfreda C, Polasky S, Rockström J, Sheehan J, Siebert S, Tilman D, Zaks DPM (2011) Solutions for a cultivated planet. Nature 478:337-342. https://doi.org/10.1038/ nature 10452PubMedGoogleScholar

Frankham R (1995) Effective population size/adult population size ratios in wildlife: a review. Genet Res 66:95-107. https://doi.org/10.1017/ s0016672300034455 PubMed Google Scholar

Franklin, I. R. Evolutionary change in small populations. (1980). Google Scholar

Fry JD (1990) Trade-offs in fitness on different hosts: evidence from a selection experiment with a phytophagous mite. Am Nat 136:569580. https://doi.org/10.1086/285116GoogleScholar

Futuyma DJ, Agrawal AA (2009) Macroevolution and the biological diversity of plants and herbivores. Proc Natl Acad Sci 106:18054 18061. https://doi.org/10.1073/pnas.0904106106 PubMed Google Scholar

Gibson CM, Hunter MS (2010) Extraordinarily widespread and fantastically complex: comparative biology of endosymbiotic bacterial and fungal mutualists of insects. Ecol Lett 13:223-234. https://doi.org/ 10.1111/j.1461-0248.2009.01416.x PubMed Google Scholar

Gobbi P, Martinez-Sanchez A, Rojo S (2013) The effects of larval diet on adult life-history traits of the black soldier fly, Hermetia illucens (Diptera: Stratiomyidae). Eur J Entomol 110:461. https://doi.org/ 10.14411/eje.2013.061 Google Scholar

Hanelt P (2001) Mansfeld's encyclopedia of agricultural and horticultural crops:(except ornamentals). Springer Science \& Business Media Google Scholar

Hazel LN (1943) The genetic basis for constructing selection indexes. Genetics 28:476-490 Pub Med Google Scholar

Hazel LN, Lush JL (1942) The efficiency of three methods of selection. J Hered 33:393-399. https://oi.org/10.1093/oxfordjournals.jhered. a105102 Google Scholar

Hoogwijk M, Faaij A, van den Broek R, Berndes G, Gielen D, Turkenburg W (2003) Exploration of the ranges of the global potential of biomass for energy. Biomass Bioenergy 25:119-133. https://doi.org/10.1016/S0961-9534(02)00191-5GoogleScholar

Hoy MA (1976) Genetic improvement of insects: fact or fantasy. Environ Entomol 5:833-839. https://doi.org/10.1093/ee/5.5. 833GoogleScholar

Husseneder C, Grace JK (2005) Genetically engineered termite gut bacteria (Enterobacter cloacae) deliver and spread foreign genes in termite colonies. Appl Microbiol Biotechnol 68:360-367. https://doi. org/10.1007/s00253-005-1914-5 PubMed Google Scholar

Jensen K, Kristensen TN, Heckmann L-H, Sørensen JG (2017) Breeding and maintaining high-quality insects. In: Insects as food and feed. Wageningen Academic Publishers, pp 175-198 Google Scholar

Kabongo JD (2013) Waste valorization. In: Encyclopedia of corporate social responsibility. Springer, pp 2701-2706. https://doi.org/10. 1007/978-3-642-28036-8 Google Scholar

Kagata H, Ohgushi T (2012) Positive and negative impacts of insect frass quality on soil nitrogen availability and plant growth. Popul Ecol 54: 75-82. https://doi.org/10.1007/s10144-011-0281-6GoogleScholar

Kirkpatrick M, Bataillon T (1999) Artificial selection on phenotypically plastic traits. Genet Res 74:265-270. https://doi.org/10.1017/ s0016672399004115 PubMed Google Scholar

Kusch S, Udenigwe CC, Cavinato C, Gottardo M, Micolucci F (2015) Value-added utilization of agro-industrial residues. Adv Food Biotechnol 415 Google Scholar

Leong SY, Kutty SRM, Tan CK, Tey LH (2015) Comparative study on the effect of organic waste on lauric acid produced by Hermetia illucens larvae via bioconversion. J Eng Sci Technol 10:52-63 Google Scholar

Li W et al (2015) Potential biodiesel and biogas production from corncob by anaerobic fermentation and black soldier fly. Bioresour Technol 194:276-282. https://doi.org/10.1016/j.biortech.2015.06.112 PubMed Google Scholar

Lim SL, Lee LH, Wu TY (2016) Sustainability of using composting and vermicomposting technologies for organic solid waste 
biotransformation: recent overview, greenhouse gases emissions and economic analysis. J Clean Prod 111:262-278. https://doi.org/10. 1016/j.jclepro.2015.08.083GoogleScholar

Lou XF, Nair J (2009) The impact of landfilling and composting on greenhouse gas emissions - a review. Bioresour Technol 100: 3792-3798. https://doi.org/10.1016/j.biortech.2008.12. 006GoogleScholar

Łukasik P, Guo H, van Asch M, Henry LM, Godfray HCJ, Ferrari J (2015) Horizontal transfer of facultative endosymbionts is limited by host relatedness. Evolution 69:2757-2766. https://doi.org/10. 1111/evo.12767PubMedGoogleScholar

Lundy ME, Parrella MP (2015) Crickets are not a free lunch: protein capture from scalable organic side-streams via high-density populations of Acheta domesticus. PLoS One 10:e118785. https://doi.org/ 10.1371/journal.pone.0118785GoogleScholar

Lush JL (1943) Animal breeding plans. Anim Breed Plans. https://doi. org/10.1086/395356GoogleScholar

Makkar HP, Tran G, Heuzé V, Ankers P (2014) State-of-the-art on use of insects as animal feed. Anim Feed Sci Technol 197:1-33. https://doi. org/10.1016/j.anifeedsci.2014.07.008GoogleScholar

Manurung R, Supriatna A, Esyanthi RR, Putra RE (2016) Bioconversion of rice straw waste by black soldier fly larvae (Hermetia illucens L.): optimal feed rate for biomass production. J Entomol Zool Stud 4: 1036-1041 Google Scholar

Mason CJ, Raffa KF (2014) Acquisition and structuring of midgut bacterial communities in gypsy moth (Lepidoptera: Erebidae) larvae. Environ Entomol 43:595-604. https://doi.org/10.1603/EN14031 PubMed Google Scholar

McCarty R (2017) Cross-fostering: elucidating the effects of gene $\times$ environment interactions on phenotypic development. Neurosci Biobehav Rev 73:219-254. https://doi.org/10.1016/j.neubiorev. 2016.12.025 Pub Med Google Scholar

McLeod A (2011) World livestock 2011-livestock in food security. Food and Agriculture Organization of the United Nations (FAO) Google Scholar

Meats A, Holmes HM, Kelly GL (2004) Laboratory adaptation of Bactrocera tryoni (Diptera: Tephritidae) decreases mating age and increases protein consumption and number of eggs produced per milligram of protein. Bull Entomol Res 94:517-524. https://doi. org/10.1079/ber2004332 PubMed Google Scholar

Melillo ED (2013) Global entomologies: insects, empires, and the 'synthetic age' in world history. Past Present 223:233-270. https://doi. org/10.1093/pastj/gtt026GoogleScholar

Meyer RS, DuVal AE, Jensen HR (2012) Patterns and processes in crop domestication: an historical review and quantitative analysis of 203 global food crops. New Phytol 196:29-48. https://doi.org/10.1111/j. 1469-8137.2012.04253.x PubMed Google Scholar

Meyers LA, Bull JJ (2002) Fighting change with change: adaptive variation in an uncertain world. Trends Ecol Evol 17:551-557. https:// doi.org/10.1016/s0169-5347(02)02633-2GoogleScholar

Moczek AP (2010) Phenotypic plasticity and diversity in insects. Philos Trans R Soc B Biol Sci 365:593-603. https://doi.org/10.1098/rstb. 2009.0263 Google Scholar

Montagna M, Mereghetti V, Gargari G, Guglielmetti S, Faoro F, Lozzia G, Locatelli D, Limonta L (2016) Evidence of a bacterial core in the stored products pest Plodia interpunctella: the influence of different diets. Environ Microbiol 18:4961-4973. https://doi.org/10.1111/ 1462-2920.13450 PubMed Google Scholar

Mueller UG, Sachs JL (2015) Engineering microbiomes to improve plant and animal health. Trends Microbiol 23:606-617. https://doi.org/10. 1016/j.tim.2015.07.009 PubMed Google Scholar

Nakamura S, Ichiki RT, Shimoda M, Morioka S (2016) Small-scale rearing of the black soldier fly, Hermetia illucens (Diptera: Stratiomyidae), in the laboratory: low-cost and year-round rearing. Appl Entomol Zool 51:161-166. https://doi.org/10.1007/s13355017-0542-8.GoogleScholar
Nguyen TT, Tomberlin JK, Vanlaerhoven S (2015) Ability of black soldier fly (Diptera: Stratiomyidae) larvae to recycle food waste. Environ Entomol 44:406-410. https://doi.org/10.1093/ee/ nvv002PubMedGoogleScholar

Oliver MJ, Petrov D, Ackerly D, Falkowski P, Schofield OM (2007) The mode and tempo of genome size evolution in eukaryotes. Genome Res 17:594-601. https://doi.org/10.1101/gr.6096207GoogleScholar

Oonincx DG, De Boer IJ (2012) Environmental impact of the production of mealworms as a protein source for humans - a life cycle assessment. PLoS One 7:e51145. https://doi.org/10.1371/journal.pone. 0051145 PubMed Google Scholar

Oonincx DG, Van Broekhoven S, Van Huis A, van Loon JJ (2015) Feed conversion, survival and development, and composition of four insect species on diets composed of food by-products. PLoS One 10: e0144601. https://doi.org/10.1371/journal.pone.0144601 PubMed Google Scholar

Ortiz JC et al (2016) Insect mass production technologies. In: Insects as sustainable food ingredients. Elsevier, pp 153-201. https://doi.org/ 10.1016/B978-0-12-802856-8.00006-5 Google Scholar

Palma L, Ceballos SJ, Johnson PC, Niemeier D, Pitesky M, VanderGheynst JS (2018) Cultivation of black soldier fly larvae on almond byproducts: impacts of aeration and moisture on larvae growth and composition. J Sci Food Agric 98:5893-5900. https:// doi.org/10.1002/jsfa.9252 PubMed Google Scholar

Parfitt J, Barthel M, Macnaughton S (2010) Food waste within food supply chains: quantification and potential for change to 2050 . Philos Trans R Soc B Biol Sci 365:3065-3081. https://doi.org/10. 1098/rstb.2010.0126PubMedGoogleScholar

Pérez-Cobas AE et al (2015) Diet shapes the gut microbiota of the omnivorous cockroach Blattella germanica. FEMS Microbiol Ecol 91: fiv022. https://doi.org/10.1093/femsec/fiv022 Pub Med Google Scholar

Perlack RD et al (2005) Biomass as feedstock for a bioenergy and bioproducts industry: the technical feasibility of a billion-ton annual supply. Oak Ridge National Lab TN. https://doi.org/10.2172/ 1218316

Pigliucci M (2001) Phenotypic plasticity: beyond nature and nurture. JHU Press. https://doi.org/10.5840/tpm20021941 Google Scholar

Rezzadori K, Benedetti S, Amante ER (2012) Proposals for the residues recovery: orange waste as raw material for new products. Food Bioprod Process 90:606-614. https://doi.org/10.1016/j.fbp.2012. 06.002GoogleScholar

Rumpold BA, Klocke M, Schlüter O (2017) Insect biodiversity: underutilized bioresource for sustainable applications in life sciences. Reg Environ Chang 17:1445-1454. https://doi.org/10.1007/ s10113-016-0967-6 Google Scholar

Salomone R, Saija G, Mondello G, Giannetto A, Fasulo S, Savastano D (2017) Environmental impact of food waste bioconversion by insects: application of life cycle assessment to process using Hermetia illucens. J Clean Prod 140:890-905. https://doi.org/10.1016/j. jclepro.2016.06.154GoogleScholar

Sánchez-Bayo F, Wyckhuys KA (2019) Worldwide decline of the entomofauna: a review of its drivers. Biol Conserv 232:8-27. https://doi. org/10.1016/j.biocon.2019.01.020 Google Scholar

Santos M, Fowler K, Partridge L (1994) Gene-environment interaction for body size and larval density in Drosophila melanogaster: an investigation of effects on development time, thorax length and adult sex ratio. Heredity 72:515-521. https://doi.org/10.1038/hdy.1994. 69 PubMed Google Scholar

Scheuring I, Yu DW (2012) How to assemble a beneficial microbiome in three easy steps. Ecol Lett 15:1300-1307. https://doi.org/10.1111/j. 1461-0248.2012.01853.x PubMed Google Scholar

Schneider JR, Chadee DD, Mori A, Romero-Severson J, Severson DW (2011) Heritability and adaptive phenotypic plasticity of adult body size in the mosquito Aedes aegypti with implications for dengue 
vector competence. Infect Genet Evol 11:11-16. https://doi.org/10. 1016/j.meegid.2010.10.019 PubMed Google Scholar

Schott ABS, Wenzel H, la Cour Jansen J (2016) Identification of decisive factors for greenhouse gas emissions in comparative life cycle assessments of food waste management - an analytical review. J Clean Prod 119:13-24. https://doi.org/10.1016/j.jclepro.2016.01. 079GoogleScholar

Schutze MK et al (2015) Effects of laboratory colonization on Bactrocera dorsalis (Diptera, Tephritidae) mating behaviour:'what a difference a year makes'. ZooKeys 369. https://doi.org/10.3897/zookeys.540. 9770 PubMed Google Scholar

Sen BK, Robertson A (1964) An experimental examination of methods for the simultaneous selection of two characters, using Drosophila melanogaster. Genetics 50:199 PubMed Google Scholar

Smetana S, Palanisamy M, Mathys A, Heinz V (2016) Sustainability of insect use for feed and food: life cycle assessment perspective. J Clean Prod 137:741-751. https://doi.org/10.1016/j.jclepro.2016. 07.148GoogleScholar

Stearns SC, Koella JC (1986) The evolution of phenotypic plasticity in life-history traits: predictions of reaction norms for age and size at maturity. Evolution 40:893-913. https://doi.org/10.1111/j.15585646.1986.tb00560.x PubMed Google Scholar

Stork NE (2018) How many species of insects and other terrestrial arthropods are there on Earth? Annu Rev Entomol 63:31-45. https://doi. org/10.1146/annurev-ento-020117-043348 PubMed Google Scholar

Strauss SY, Lau JA, Carroll SP (2006) Evolutionary responses of natives to introduced species: what do introductions tell us about natural communities? Ecol Lett 9:357-374. https://doi.org/10.1111/j.14610248.2005.00874.x PubMed Google Scholar

Surendra KC, Olivier R, Tomberlin JK, Jha R, Khanal SK (2016) Bioconversion of organic wastes into biodiesel and animal feed via insect farming. Renew Energy 98:197-202. https://doi.org/10. 1016/j.renene.2016.03.022 CrossRef Google Scholar

Tabashnik BE (1994) Evolution of resistance to Bacillus thuringiensis. Annu Rev Entomol 39:47-79 Google Scholar

Taracena ML et al (2015) Genetically modifying the insect gut microbiota to control Chagas disease vectors through systemic RNAi. PLoS Negl Trop Dis 9:e0003358. https://doi.org/10.1371/journal.pntd. 0003358 PubMed Google Scholar

Turhollow A, Perlack R, Eaton L, Langholtz M, Brandt C, Downing M, Wright L, Skog K, Hellwinckel C, Stokes B, Lebow P (2014) The updated billion-ton resource assessment. Biomass Bioenergy 70 : 149-164. https://doi.org/10.1016/j.biombioe.2014.09. 007GoogleScholar

Ushakova NA, Bastrakov AI, Karagodin VP, Pavlov DS (2018) Specific features of organic waste bioconversion by Hermetia illucens fly larvae (Diptera: Stratiomyidae, Linnaeus, 1758). Biol Bull Rev 8: 533-541. https://doi.org/10.1134/s2079086418060117 Google Scholar

Van Broekhoven S, Oonincx DG, Van Huis A, Van Loon JJ (2015) Growth performance and feed conversion efficiency of three edible mealworm species (Coleoptera: Tenebrionidae) on diets composed of organic by-products. J Insect Physiol 73:1-10. https://doi.org/10. 1016/j.jinsphys.2014.12.005 PubMed Google Scholar
Van Huis A (2013) Potential of insects as food and feed in assuring food security. Annu Rev Entomol 58:563-583. https://doi.org/10.1146/ annurev-ento-120811-153704 PubMed Google Scholar

Van Huis A et al (2013) Edible insects: future prospects for food and feed security. BioOne 171 Google Scholar

Vantomme P, Mertens E, van Huis A, Klunder H (2012) Assessing the potential of insects as food and feed in assuring food security: summary report. Food and Agricultural Organization of the United Nations. For Dep Rome Italy. https://doi.org/10.1146/annurevento-120811-153704 PubMed Google Scholar

Via S (1986) Genetic covariance between oviposition preference and larval performance in an insect herbivore. Evolution 40:778-785. https://doi.org/10.2307/2408462 PubMed Google Scholar

Via $S$ et al (1995) Adaptive phenotypic plasticity: consensus and controversy. Trends Ecol Evol 10:212-217. https://doi.org/10.1016/s01695347(00)89061-8 PubMed Google Scholar

Vicoso B, Bachtrog D (2015) Numerous transitions of sex chromosomes in Diptera. PLoS Biol 13:e1002078. https://doi.org/10.1371/journal. pbio.1002078 Pub Med Google Scholar

Wang Y-S, Shelomi M (2017) Review of black soldier fly (Hermetia illucens) as animal feed and human food. Foods 6:91. https://doi. org/10.3390/foods6100091PubMedGoogleScholar

Whitman D (2009) Phenotypic plasticity of insects: mechanisms and consequences. CRC Press. https://doi.org/10.1201/b10201 Google Scholar

Wilkinson JM (2011) Re-defining efficiency of feed use by livestock. Animal 5:1014-1022. https://doi.org/10.1017/ S175173111100005XPubMedGoogleScholar

Yen AL, Van Itterbeeck J (2016) No taxonomists? No progress. Wageningen Academic Publishers. https://doi.org/10.3920/ jiff2016.x004 https://scholar.google.com/scholar?cluster= $17447611645401751467 \&$ hl $=$ en\&as_sdt $=0,5$

Yu G, Cheng P, Chen Y, Li Y, Yang Z, Chen Y, Tomberlin JK (2011) Inoculating poultry manure with companion bacteria influences growth and development of black soldier fly (Diptera: Stratiomyidae) larvae. Environ Entomol 40:30-35. https://doi.org/ 10.1603/EN10126 PubMed Google Scholar

Zeder MA (2012) The domestication of animals. J Anthropol Res 68: 161-190. https://doi.org/10.3998/jar.0521004.0068. 201 GoogleScholar

Zhang Z-Q (2011) Animal biodiversity: an outline of higher-level classification and survey of taxonomic richness. Magnolia press. https:// doi.org/10.11646/zootaxa.3148.1.2 Google Scholar

Zheng L et al (2013) Bacteria mediate oviposition by the black soldier fly, Hermetia illucens (L.), (Diptera: Stratiomyidae). Sci Rep 3:2563. https://doi.org/10.1038/srep02563 PubMed Google Scholar

Zhou F, Tomberlin JK, Zheng L, Yu Z, Zhang J (2013) Developmental and waste reduction plasticity of three black soldier fly strains (Diptera: Stratiomyidae) raised on different livestock manures. J Med Entomol 50:1224-1230. https://doi.org/10.1603/me13021 Pub Med Google Scholar

Zweigle CA (2010) Pistachio byproducts as substrate for shiitake mushrooms. California State University, Fresno Google Scholar

Publisher's note Springer Nature remains neutral with regard to jurisdictional claims in published maps and institutional affiliations. 